nguy cơ UTCTC cao gấp 495,4 lần những người không nhiễm với 95\%CI: 104,26-2354,3 ( $\mathrm{p}<$ $0,05)$. Nhiễm HPV16 hoặc HPV18 có nguy cơ UTCTC cao hơn những người không nhiễm ( $p$ < $0,001)$. HPV 16 gặp chủ yếu trong UTBM vảy, HPV 18 gặp chủ yếu ở UTBM tuyến và tuyến vảy $(p=$ $0,008)$. Như vậy, nhiễm HPV NCC có mối liên quan chặt chẽ với UTCTC đă̆c biệt là HPV 16 và HPV 18. Kết quả này có thể cung cấp thông tin hữu ích cho việc phòng chống UTCTC ở Việt Nam.

\section{KẾT LUẬN}

Tỷ lê̂ nhiễm HPV ở những BN đến khám phu khoa tại Bệnh viện $K$ từ 5/2019 đến $3 / 2020$ ở mức độ trung bình (13,4\%)phù hợp với tỷ lệ nhiễm HPV trong nước.Nhóm BN nhiễm 12 type NCC khác (type 16, type 18) chiếm 72,9\%, chỉ nhiễm HPV16 là $13,6 \%$ và HPV18 là $7,1 \%$ trong 285 trường hợp HPV (+). Có mối liên quan chặt chẽ giữa nguy cơ bất thường tế bào CTC và nguy cơ UTCTC với nhiễm HPV NCC, đặc biệt là 2 type HPV 16 và HPV $18(p<0,01)$.

\section{TÀI LIẸU THAM KHẢO}

1. Weaver BA. Epidemiology and natural history of genital human papillomavirus infection. J Am Osteopath Assoc. 2006; 106: S2-8.

2. Ferlay J, Shin HR, Bray F, Forman D, Mathers
C, Parkin DM. Estimates of worldwide burden of cancer in 2008: GLOBOCAN 2008. Int J Cancer. 2010; 127: 2893-2917.

3. Lê Quang Vinh, Đàm Thị Quỳnh Liên, Lưu Thị Hông và cộng sứ. Tình trạng nhiếm HPV cao ở những phụ nữ có tổn thương tân sản nội biểu mô và ung thư cổ tử cung tại Bệnh viện Phụ sản Trung Ương. 2017.

4. Clifford G, Franceschi S, Diaz M, Munoz N, Villa LL. Chapter 3: HPV type-distribution in women with and without cervical neoplastic diseases. Vaccine. 2006; 24 (3): 26-34.

5.Vũ Văn Tâm, Phan Thị Thănh Lan và Lưu Vũ Dũng. Nghiến cứu tỷ lể nhiếm HPV ở bệnh nhân có tổn thương cổ tử cung tại Bệnh viện Phụ sản Hải Phòng băng kỹ thuật Real - Time PCR và Reverse Dot Blot Hybridization. 2017.

6. Bùi Thị Thu Hương và Lò Minh Trọng. Nghiên cứu tỷ lệ nhiễm HPV typ nguy cơ cao ở bệnh nhân tại bệnh viên Trung ương Thái Nguyên năm 2019 2020.Tạp chí Y học Việt Nam. 2021; 2(498): 65-68.

7. Alacam $\mathbf{S}$ và Bakir A. Human Papillomavirus Prevalence and Genotype Distribution in Cervical Swab Samples in Istanbul, Turkey. J Infect Dev Ctries. 2021; 15:1190-1196.

8. So KA, Hong JH, Lee JK. Human Papillomavirus Prevalence and Type Distribution Among 968 Women in South Korea. J Cancer Prev. 2016;21(2):104-109.

9. Hoàng Thị Thanh Huyên và Tạ Thành Văn. Sự phân bố genotýp của Human papilloma virus trên gái mại dâm tại miền bắc Việt Nam. Tạp chí Nghiên cứu Y học. 2011; 72(1): 7- 11.

\title{
GIÁ TRI THANG ĐIỂM BAP-65 VÀ DECAF TRONG TIÊN LƯỢNG TƯ VONG VÀ NHU CẦU THỞ MÁY Ở BÊ̂NH NHÂN BỆNH PHỔI TẮC NGHẼN MẠN TÍNH TRONG ĐợT CẤP
}

Nguyễn Văn Long', Nguyễn Lam², Tạ Bá Thắng ${ }^{2}$

\section{TÓM TẮT}

Mục tiêu nghiên cứu: xác định giá trị thang điểm BAP-65 và DECAF trong tiên lượng tử vong và nhu câu thở máy ở bệnh nhân bệnh phổi tắc nghẽn mạn tính trong đợt cấp. Đối tượng và phương pháp: nghiên cứu tiến cứu theo dõi dọc trên 87 bênh nhân được xác định chẩn đoán BPTNMTT đợt cấp điêu trị tại Trung tâm Nội hô hấp, bệnh viện Quẩn y 103 từ tháng 9/2020 - tháng 5/2021. Các bệnh nhân được khám lâm sàng, làm xét nghiệm, đánh giá các thang điểm BAP-65, DECAF tại thời điểm nhập viện. Đánh giá kết quả điêu trị đợt cấp: tốt, chỉ định thở máy và

\footnotetext{
${ }^{1}$ Viện Y học cổ truyền Quân đội,

2Bệnh viện Quân y 103, Học viện Quân y

Chịu trách nhiệm chính: Nguyến Văn Long

Email: vanlongbsqy@gmail.com

Ngày nhận bài: 8.9.2021

Ngày phản biện khoa học: 25.10.2021

Ngày duyệt bài: 9.11.2021
}

tử vong. Phân tích giá trị các thang điểm trong tiên lượng tử vong và nhu câu thở máy. Kết quả: Điểm DECAF ở ngưỡng $>2$ điểm có giá trị tiên lượng tử vong với độ nhạy $100 \%$, độ đặc hiệu: $89,2 \%$, diện tích dưới đường cong ROC: 0,956 (95\%CI: 0,91-1,00). Điểm BAP-65 ớ ngưỡng $>3$ điểm có giá trị tiên lượng tử vong với độ nhạy $75 \%$, độ đặc hiệu: $94 \%$, diện tích dưới đường cong ROC: 0,93 (95\%CI: 0,84-1,0). Điểm DECAF ở ngưỡng $>1$ điểm có giá trị tiên lượng nhu câuu thở máy với độ nhạy $100 \%$, độ đặc hiệu: $80,5 \%$, diện tích dưới đường cong ROC: 0,902 (95\%CI: 0,828$0,976)$. Điểm BAP-65 ở ngưỡng $>1$ điểm có giá trị tiên lượng nhu cầu thở máy với độ nhạy $60 \%$, độ đặc hiểu: $93,9 \%$, diên tích dưới đường cong ROC: 0,912 (95\%CI: 0,818-1,0). Kết luâan: hai thang điểm DECAF và $\mathrm{BAP}-65$ đều có giá trị tiền lượng tư vong và nhu câu thở máy ở các bệnh nhân BPTNMT trong đợt cấp, nhưng thang điểm DECAF có giá trị tiên lượng cao hơn.

Tư khóa: Đợt cấp bệnh phổi tắc nghẽn mạn tính; Thang điểm DECAF, BAṔ-65; Tử vong; Nhu câu thở máy. 


\section{SUMMARY \\ VALUE OF THE DECAF AND BAP-65 SCORES IN THE PREDICTION OF MORTALITY AND NEED FOR MECHANICAL VENTILATION IN CHRONIC OBSTRUCTIVE PULMONARY DISEASE PATIENT WITH ACUTE EXACERBATION}

Object: Assess the value of the DECAF and BAP65 scores in the prediction of mortality and need for mechanical ventilation in chronic obstructive pulmonary disease patient (COPD) with acute exacerbation. Subject and method: A Observation, prospective study in 87 patients AECOPD were admitted to Respiratory Center of 103 Hospital, from $9 / 2020$ to $5 / 2021$. The patients were clinically examined, tested, and assessed the BAP-65 and DECAF scores at the time of admission. Evaluation of treatment outcomes for exacerbations: good, indicated for mechanical ventilation and mortality. Analysis of the value of the DECAF and BAP-65 scores in the prognosis of mortality and the need for mechanical ventilation. Results: For the predicting of mortality, DECAF score $>2$ has sensitivity and specificity that were $100 \%$ and $89.2 \%$, AUROC $=0.956(95 \% \mathrm{CI}$ : $0.91-1.00)$. BAP-65 score $>3$ has sensitivity and specificity that were $75 \%$ and $94 \%$, area under the ROC curve: 0.93 (95\%CI: 0.84-1.0). The DECAF score $>1$ has a prognostic value for the need for mechanical ventilation with sensitivity: $100 \%$, specificity: $80.5 \%$, AUROC $=0.902$ (95\%CI: $0.828-0.976)$. The BAP-65 score $>1$ has a prognostic value for the need for mechanical ventilation with sensitivity: $60 \%$, specificity: 93.9\%, AUROC= 0.912 (95\%CI: 0.8181.0). Conclusion: DECAF and BAP-65 scores have predictive value of mortality and need for mechanical ventilation in COPD patients with acute exacerbation, but DECAF score has higher prognostic value.

Key word: acute exacerbation of chronic obstructive pulmonary disease; DECAF score, BAP-65 score; Mortality; Need for mechanical ventilation .

\section{I. ĐặT VẤN ĐỀ}

Đợt cấp bệnh phổi tắc nghẽn mạn tính (BPTNMT) là một biến cố bất lợi cho bệnh nhân: tăng sự tiến triển của bênh, nguy cơ biến chứng và tử vong, tăng chi phí điều trị $[1,3,4]$. Đánh giá nguy cơ tử vong và nhu cầu thở máy ở bệnh nhân BPTNMT trong đợt cấp có vai trò quan trong trong can thiệp điều trị, tiên lượng kết quả điều trị. Một công cu dư đoán lâm sàng chính xác có thể hỗ trợ thầy thuốc đưa ra các quyết định, giúp giảm tỷ lệ tử vong và sử dụng các nguồn lực hợp lý ở bệnh nhân BPTNMT [1, 2]. Môt số nghiên cứu cho thấy vai trò của các thang điểm trong tiên lượng tử vong và nhu cầu thở máy ở bệnh nhân BPTNMT trong đợt cấp: thang điểm BODE (Body-mass index, airflow Obstruction, Dyspnea, Exercise), BAP-65 (BUN, Altered metal status, Pulse, Age $\geq 65$ ) và DECAF (Dyspnea, Eosinopenia, Consolidation, Acidemia, atrial Fibrillation). Hiện thang điểm BAP-65 do Shorr A.F. đề xuất 2011 và DECAF do Sterr J. đưa ra 2012 được quan tâm và cho thấy có nhiều ưu điểm trong tiên lượng ở bệnh nhân BPTNMT [1,2]. Tại Việt Nam chưa có nhiều nghiên cứu về giá trị của các thang điểm này trong đánh giá nguy cơ tử vong và nhu cầu thở máy ở bệnh nhân BPTNMT trong đợt cấp. Do vậy chúng tối thực hiện đề tài này với mục tiêu: xác định giá trị thang điểm BAP-65 và DECAF trong tiên lượng tử vong và nhu cầu thở máy ở bệnh nhân bệnh phổi tắc nghẽn mạn tính trong đợt cấp.

\section{II. ĐỐI TƯỢNG VÀ PHƯƠNG PHÁP NGHIÊN CỨU}

2.1. Đối tượng. Gồm 87 bệnh nhân BPTNMT đợt cấp điều trị tại Trung tâm nội hô hấp, bệnh viện Quân Y 103 từ tháng 9/2020 đến tháng 5/2021. Các bênh nhân được chẩn đoán xác định BPTNMT và đợt cấp theo tiêu chuẩn của GOLD (2019). Loại trừ các bệnh nhân mắc các bênh kết hợp như lao phổi, ung thư phổi, hen phế quản, bựi phổi, nấm phổi, nhiễm HIV.

2.2. Phương pháp. Nghiên cứu tiến cứu, mô tả, theo dõi dọc, chọn mẫu thuận tiện. Các bệnh nhân được khám lâm sàng, làm các xét nghiệm tại các thời điểm: khi nhập viện, trong quá trình điều trị và tại thời điểm trước tử vong hay phải thở máy.

Đánh giá các thang điểm BAP-65, DECAF tại thời điểm nhâp viện: tính điểm BAP-65 theo tiêu chuẩn của Shorr A.F. (2011)[1] và điểm DECAF theo tiêu chuẩn Sterr J. (2012) [2]. Các bệnh nhân được điều trị đợt cấp theo phác đồ của Bộ $y$ tế (2018) [3].

Chỉ định thở máy theo tiêu chuẩn của Bộ y tế (2018) [3]. Đánh giá kết quả điều trị đợt cấp theo các mức: tốt (bênh nhân hết đợt cấp, ra viện), nhu cầu thở máy (bệnh nhân phải chỉ định thở máy để điều trị đợt cấp), tử vong (bệnh nhân tử vong trong đợt cấp).

Nhập và xử lý số liệu bằng phần mềm SPSS 20.0; thuật toán sử dụng: tính độ nhạy (Se), độ đặc hiệu (Sp), diện tích dưới đường cong (AUROC), hệ số tương quan (r), so sánh 2 tỷ lệ.

\section{KẾT QUẢ NGHIÊN CỨU}

Bảng 1: Một số đặc điểm chung của bệnh nhân nghiên cứu

\begin{tabular}{|c|c|c|c|}
\hline \multicolumn{2}{|c|}{} & Số lượng (n) & Tỉ lệ (\%) \\
\hline \multirow{2}{*}{ Giới } & Nam & 82 & 94,3 \\
\cline { 2 - 4 } & Nữ & 5 & 5,7 \\
\hline \multicolumn{2}{|c|}{ Hút thuốc } & 72 & 82,8 \\
\hline \multicolumn{2}{|c|}{ Tuối $(X \pm$ SD) } & \multicolumn{2}{|c|}{$69,71 \pm 8,72$} \\
\hline \multicolumn{2}{|c|}{ BMI $(X \pm$ SD) } & \multicolumn{2}{|c|}{$19,75 \pm 3,26$} \\
\hline
\end{tabular}




\begin{tabular}{|c|c|c|}
\hline Thiếu cân & 33 & 37,9 \\
\cline { 2 - 3 } Thừa cân & 15 & 17,2 \\
\hline Tử vong & 4 & 4,6 \\
\hline Thở máy & 5 & 5,7 \\
\hline
\end{tabular}

Bệnh nhân nam: 82 bệnh nhân chiếm $94,3 \%$. Tiên sử hút thuốc lá >10 bao-năm là 72 bệnh nhân, chiến $82,8 \%$. Tuổi trung bình của các bệnh nhân là $69,71 \pm 8,72$. BMI trung bình là $19,75 \pm 3,26$; trong đó 33 bệnh nhân thiếu cân (BMI < 18) chiếm 37,9\%. Có 4 bệnh nhân tử vong chiếm $4,6 \%$ và 5 bệnh nhân phải thở máy chiếm $5,7 \%$.

Bảng 2: Môi liên quan giữa điểm DECAF và BAP-65 với kêt cỵc tử vong

\begin{tabular}{|c|c|c|c|}
\hline \multirow{2}{*}{$\begin{array}{c}\text { Thang } \\
\text { điểm }\end{array}$} & \multicolumn{2}{|c|}{ Kết quả điêu trị } & \multirow[b]{2}{*}{ p } \\
\hline & Tốt (n) & Tử vong (n) & \\
\hline $\begin{array}{l}\text { DECAF Trung } \\
\text { vi (Q1-Q3) }\end{array}$ & $\begin{array}{c}83 \\
1(0-1)\end{array}$ & $\begin{array}{c}4 \\
4(3,25-4)\end{array}$ & 0,001 \\
\hline $\begin{array}{l}\text { BAP-65 Trung } \\
\text { vi (Q1-Q3) }\end{array}$ & $\begin{array}{c}83 \\
2(2-3)\end{array}$ & $\begin{array}{c}4 \\
4(3,25-4,75)\end{array}$ & 02 \\
\hline
\end{tabular}

Điểm DECAF và BAP-65 có liên quan đến kết cục tử vong: điểm DECAF và BAP-65 ở nhóm bệnh nhân tử vong cao hơn rõ rệt so với nhóm bệnh nhân điều trị tốt $(p<0,05)$.

Bảng 3: Môi tương quan giữa điểm sô BAP-65 và DECAF với tử vong

\begin{tabular}{|c|c|c|c|}
\hline \multicolumn{2}{|c|}{ Tương quan } & $\mathbf{r}$ & $\mathbf{p}$ \\
\hline DECAF & Tứ vong & 0,353 & $\mathrm{p}=0,001$ \\
\hline BAP-65 & Tử vong & 0,337 & $\mathrm{p}=0,001$ \\
\hline
\end{tabular}

Có mối tương quan thuận mức độ vừa giữa kết cục tử vong với điểm BAP-65 $(r=0,337$, $p=0,001)$, và điểm DECAF $(r=0,353, p=0,001)$
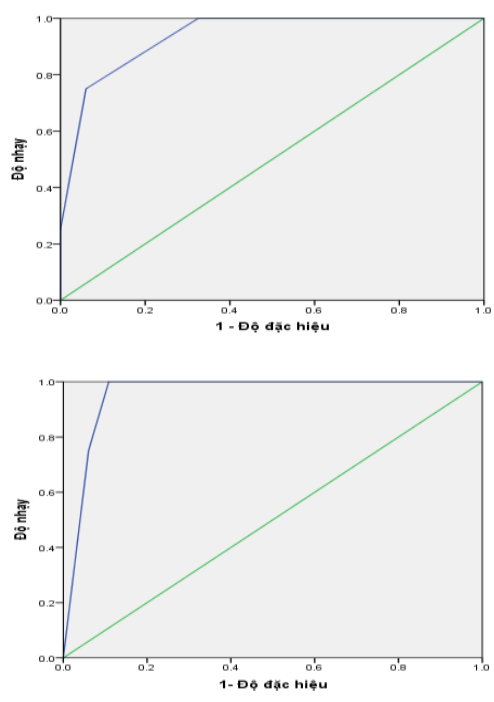

Biêu đồ 1: Đường cong ROC biểu thị liên quan giữa điểm DECAF (bên trái) và điểm BAP-65 (bên phải) với kêt cục tử vong
Điểm DECAF ở ngưỡng >2 điểm có giá trị tiên lượng tử vong với độ nhạy $100 \%$, độ đặc hiệu: $89,2 \%$, diện tích dưới đường cong ROC: 0,956 (95\%CI: 0,91 - 1,00). Điểm BAP-65 ở ngưỡng >3 điểm có giá trị tiên lượng tử vong với độ nhạy $75 \%$, độ đặc hiệu: $94 \%$, diện tích dưới đường cong ROC: 0,93 (95\%CI: 0,84-1,0).

Bảng 4: Môi liên quan giứa điếm DECAF và BAP-65 với nhu cầu thở máy

\begin{tabular}{|c|c|c|c|}
\hline \multirow[b]{2}{*}{$\begin{array}{l}\text { Thang } \\
\text { điểm }\end{array}$} & \multicolumn{2}{|c|}{ Nhu câu thở máy } & \multirow[b]{2}{*}{ p } \\
\hline & $\begin{array}{c}\text { Không } \\
\text { thở } \\
\text { máy(n) }\end{array}$ & $\begin{array}{l}\text { Thở } \\
\text { máy(n) }\end{array}$ & \\
\hline $\begin{array}{l}\text { DECAF } \\
\text { Trung vị } \\
\text { (Q1-Q3) }\end{array}$ & $\begin{array}{c}82 \\
1(0-1)\end{array}$ & $\begin{array}{c}5 \\
3(2-4)\end{array}$ & 0,001 \\
\hline $\begin{array}{l}\text { BAP-65 } \\
\text { Trung vị } \\
\text { (Q1-Q3) }\end{array}$ & $\begin{array}{c}82 \\
2(2-3)\end{array}$ & $\begin{array}{c}5 \\
4(3-4)\end{array}$ & 0,001 \\
\hline
\end{tabular}

Điểm DECAF và BAP-65 liên quan đến nhu cầu thở máy: điểm DECAF và BAP-65 ở nhóm bệnh nhân có nhu cầu thở máy đều cao hơn rõ rệt so với nhóm bệnh nhân không phải thở máy $(\mathrm{p}<0,05)$

Bảng 5: Môi tương quan giữa điểm BAP65 và DECAF với nhu cầu thở máy

\begin{tabular}{|c|c|c|c|}
\hline \multicolumn{2}{|c|}{ Tương quan } & r & p \\
\hline DECAF & Thở máy & 0,346 & 0,001 \\
\hline BAP-65 & Thở máy & 0,354 & 0,001 \\
\hline
\end{tabular}

Có mối tương quan thuận mức độ vừa giữa nhu cầu thở máy với điểm BAP-65 $(\mathrm{r}=0,354$, $p=0,001)$ và điểm $\operatorname{DECAF}(r=0,346, p=0,001)$
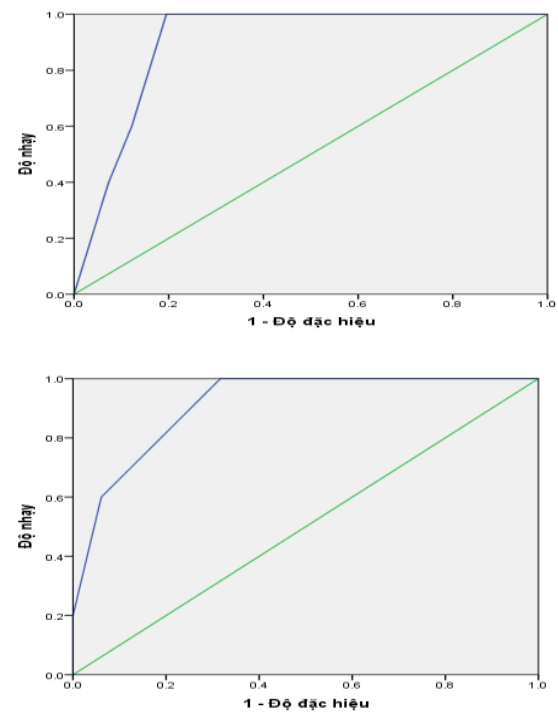

Biểu đồ 2: Đường cong ROC biểu thị liên quan giữa điểm DECAF (bên trái) và điểm BAP-65 (bên phải) với nhu cầu thở máy 
Điểm DECAF ở ngưỡng $>1$ điểm có giá trị tiên lượng nhu câuu thở máy với độ nhạy $100 \%$, độ đặc hiệu: $80,5 \%$, diện tích dưới đường cong ROC: 0,902 (95\%CI: 0,828-0,976). Điểm BAP65 ở ngưỡng $>1$ điểm có giá trị tiên lượng nhu cầu thở máy với độ nhạy $60 \%$, độ đặc hiệu: 93,9\%, diện tích dưới đường cong ROC: 0,912 (95\%CI: 0,818-1,0).

\section{BÀN LUẬN}

4.1. Đặc điểm chung bệnh nhân nghiên cứu. Tỷ lệ bệnh nhân nam giới trong nhóm nghiên cứu chiếm 94,3\%, với độ tuổi trung bình là $69,71 \pm 8,72$ tuối, tỷ lệ hút thuốc là $82,8 \%$ (Bảng 1). Kết quả của chúng tôi tương đồng với các nghiên cứu trong nước và quốc tế: Đào Ngọc Bằng (2019), tuổi trung bình là $65,8 \pm 6,96$, toàn bộ bệnh nhân nghiên cứu là nam [4]. Nghiên cứu của John Steer (2012) và cộng sự có tuổi trung bình là 73,1 tuổi, tỷ lệ nữ giới chiếm 53,6\% [2].

BMI trung bình của các bệnh nhân trong nghiên cứu là $19,75 \pm 3,26$, trong đó có $33 / 87$ bệnh nhân (37,9\%) thuộc nhóm thiếu cân. Đặc điểm này cũng tương tự nghiên cứu của Đà̀o Ngọc Bằng (2019) với BMI trung bình là 18,26 \pm 2,46 , bênh nhân thiếu cân chiếm chủ yếu $(60,61 \%)$ [4]. Nghiên cứu của John Steer (2012) có BMI trung bình là 24,6 [2].

Sự khác biệt này có lẽ liên quan đến vấn đề nhân chủng học giữa người châu Á và châu Âu, tuy nhiên cũng phản ánh tình trạng dinh dưỡng, điêu kiện kinh tế xã hội và chăm sóc y tế tại các quốc gia phát triển tốt hơn.

Trong nghiên cứu của chúng tôi có 4 bệnh nhân tử vong $(4,6 \%)$ ( Bảng 2). Kết quả này của chúng tôi tương đương với kết quả của Shorr (2011) là 4\% [1]. John Steer và cộng sự (2016) là 7\% [5]. Tuy nhiên tỷ lệ tử vong thấp hơn với 1 số nghiên cứu như Trần Văn Ngọc (2011) là $10 \%$ [6], Nguyễn Hải Công (2021) là 30\% [7]. Số bệnh nhân phải thở máy trong nghiên cứu của chúng tôi là 5 bệnh nhân $(5,7 \%)$, thấp hơn so với kết quả của Shorr (2011) là 9,2 \%[1]. và Trần Văn Đồng (2017) là 9,8\%[8]. Có sự khác biệt như vậy có thể do phân bố mức độ nặng đợt cấp khác nhau giữa các nghiên cứu.

4.2. Giá trị tiên lượng tử vong và nhu câu thở máy của các thang điểm. Trong nghiên cứu của chúng tôi cho thấy các bệnh nhân tử vong có điểm DECAF và BAP-65 cao hơnn các bệnh nhân có kết quả điều trị tốt, sự khác biệt này có ý nghĩa thống kê với $p<0,05$ (Bảng 2) và các thang điểm này có mối tương quan mức độ vừa giữa kết cục tử vong (điểm BAP-65 với $r=0,337, p=0,001$ và điểm DECAF với $r=0,353, p=0,001$ ) (bảng 3). Điểm DECAF ở ngưỡng $>2$ điểm có giá trị tiên lượng tử vong với độ nhạy $100 \%$, độ đặc hiệu: $89,2 \%$, diện tích dưới đường cong ROC: 0,956 (95\%CI: 0,91 1,00). Điểm BAP-65 ở ngướng >3 điểm có giá trị tiên lượng tử vong với độ nhạy $75 \%$, độ đặc hiệu: 94\%, diện tích dưới đường cong ROC: 0,93 ( $95 \% \mathrm{CI}: 0,84-1,0)$. Kết quả này tương đồng với nghiên cứu của các tác giả trong và ngoài nước $[1],[2],[9]$.

Khi nghiên cứu về khả năng tiên lượng nhu cầu thở máy ở các bệnh nhân đợt cấp BPTNMT, chúng tôi nhận thấy điểm DECAF và BAP-65 ơ nhóm bệnh nhân có nhu cầu thở máy đều cao hơn rõ rệt so với nhóm bệnh nhân không phải thở máy $(p<0,05)$ (bảng 4) và có mối tương quan thuận mức độ vừa giữa nhu cầu thở máy với điểm BAP-65 ( $r=0,354, p=0,001)$ và điểm DECAF ( $r=0,346, p=0,001)$ (bảng 5). Điểm DECAF ở ngưỡng $>1$ điểm có giá trị tiên lượng nhu câuu thở máy với độ nhạy $100 \%$, độ đặc hiệu: $80,5 \%$, diện tích dưới đường cong ROC: 0,902 (95\%CI: 0,828 - 0,976). Điểm BAP-65 ơ ngưỡng $>1$ điểm có giá trị tiên lượng nhu cầu thở máy với độ nhạy $60 \%$, độ đặc hiệu: $93,9 \%$, diện tích dưới đường cong ROC: 0,912 (95\%CI: $0,818-1,0)$. Như vậy thang điểm DECAF có giá trị tiên lượng nhu cầu thở máy cao hơn thang điểm BAP-65.

\section{KẾT LUÂN}

Từ kết quả nghiên cứu bước đầu chúng tôi rút ra kết luận như sau: hai thang điểm DECAF và $\mathrm{BAP}-65$ đều có giá trị tiên lượng tử vong và nhu cầu thở máy ở các bềnh nhân BPTNMT trong đợt cấp, nhưng thang điểm DECAF có giá trị tiên lượng cao hơn.

\section{TÀI LIÊU THAM KHẢO}

1. Shorr A.F., Sun X., Johannes R.S., (2011). Validation of a novel risk score for severity of illness in acute exacerbations of COPD. Chest, 140(5): 1177-1183.

2. Steer J., Gibson J., Bourke S. C. (2012). The DECAF Score: predicting hospital mortality in exacerbations of chronic obstructive pulmonary disease. Thorax, 67(11): 970-6.

3. Bộ Y tế . (2018). Hướng dẫn chẩn đoán và điều trị bệnh phổi tắc nghẽn mạn tính.

4. Đào Ngọc Bằng. (2019). Nghiên cứu hiêu quả điều trị giảm thể tích phổi qua nội soi phế quản bằng van môt chiều ở bệnh nhân bệnh phổi tắc nghễn mạn tính. Luận án tiến sĩ, Học Viện Quân Y.

5. Steer J., Echevarria C., Heslop-Marshall $\mathrm{K}$. (2016). Validation of the DECAF score to predict hospital mortality in acute exacerbations of COPD. Thorax, 71(2): 133-140. 
6. Trân Văn Ngọc. (2011). Các yếu tố nguy cơ tử vong của đợt cấp copd. Tạp chí y học thành phố Hồ Chí Minh, 15: 8.

7. Nguyễn Hải Công, Tạ Bá Thắng, Nguyễn Huy Lức. (2021). Study on prognostic values for mortality of clinical and subclinical factors in acute exacerbation of chronic obstructive pulmonary disease. Journal of Military Pharmaco - Medicine, 2: 7.

8. Trân Văn Đồng, Nguyển Văn Chi, Nguyễn
Ngoc Sơn. (2017). So sánh giá trị dự đoán sự cân thiết phải thông khí nhân tạo của bảng điểm BAP65 và CURB-65 ở bênh nhân đợt cấp bênh phổi tắc nghẽn man tính. Tạp chí y dược học, trường đại hoc y Huế, 7: 60-63.

9. Yousif M., El Wahsh R.A. (2016). Predicting inhospital mortality in acute exacerbation of COPD: Is there a golden score? Egyptian Journal of Chest Diseases and Tuberculosis, 65(3): 579-584.

\section{ĐÁNH GIÁ KẾT QUẢ ĐIỀU TRI TRĨ VÒNG HỖN HỢP Độ IV BẰNG PHẪU THUẬT WHITEHEAD TẠI BỆNH VIỆN TRUNG ƯƠ'NG QUÂN ĐộI 108}

Diêm Đăng Bình, Triệu Triều Dương, Hồ Hữu An, nguyễn Văn Trưởng, Vũ Ngọc Sơn, Phạm Thị Huế, Ngố Thị To, Trần Thị Hà

\section{TÓM TẮT}

Phẫu thuật Whitehead được xem là phương pháp phù hợp trong điều trị trĩ vòng hỗn hợp độ IV, tuy nhiên tỳ lệ tai biến, biến chứng còn cao. Ngày nay, với sự phát triển của các dụng cụ cầm máu giúp hạn chế được nhược điểm của phẩu thuật Whitehead. Nghiên cứu được thực hiện với mục tiểu: Đánh giá kết quả điều trị trĩ vòng hỗn hợp độ IV bằng phẫu thuật Whitehead tai Bệnh viên TWQ்Đ108. Đối tượng và phương pháp nghiện cứu: Nghiên cứu mô tả tiến cứu $55 \mathrm{BN}$ trĩ vòng hỗn hợp độ IV được điều trị bằng phẩu thuât Whitehead tai Bênh viên TWQĐ 108. Kêt quả: $72,7 \%$ bệnh nhân nam, tuổi trung bình 52,6 tuổi. $61,8 \%$ bệnh nhân được phấu thuật whitehead có sử dụng dao Ligasure và $38,2 \%$ sử dụng chày tự chế. Lượng máu mất, thời gian phẫu thuật và đau sau mổ của nhóm sử dụng Ligasure ngắn hớn so với dùng chày $(\mathrm{p}<0,05)$. Biến chứng sớm $27,3 \%$. Thời gian theo dõi xa trung bình 15,4 tháng, biến chứng xa $7,3 \%$, không bệnh nhân nào tái phát. $98,8 \%$ tự chủ hậu môn hoàn toàn tại thời điểm kết thúc nghiên cứu. Kểt luận: Cắt trĩ theo Whitehead là phương pháp hiệu quả trong điều trị trĩ vòng hỗn hợp độ IV. Việc áp dụng phương pháp cắt trĩ theo Whitehead với các dựng cự hố trợ hoặc phương tiên cầm máu tùy thuộc vào thói quen của phẩu thuật viên.

Tư khóa: Trĩ vòng, Whitehead

\section{SUMMARY}

\section{RESLTS OF TREATMENT OF GRADE IV HEMORRHOIDS BY WHITEHEAD'S HEMORRHOIDECTOMY}

Whitehead surgery is considered a suitable method to treat grade IV mixed-ring hemorrhoids, but the rate of complications is still high. Nowadays, the

*Bênh viên Trung ương Quân đôi 108

Chịu trách nhiệm chính: Diêm Đăng Bình

Email: drbinhbv108@gmail.com

Ngày nhận bài: 9.9.2021

Ngày phàn biên khoa họ: 26.10.2021

Ngày duyệt bài: 10.11.2021 development of vessel sealing devices helps to limit the disadvantages of Whitehead surgery. The study was carried out with the objective: To evaluate the results of treatment of grade IV mixed ring hemorrhoids by Whitehead surgery at 108 Central Military Hospital. Subjects and methods: Prospective descriptive study of 55 patients with grade IV mixed ring hemorrhoids treated by Whitehead surgery using Ligasure or pestle at the Department of Anal - Rectal and Pelvic Floor - 108 Central Military Hospital Results: The average age of patients was 52.6 years old, males accounted for $72.7 \%$. The mean duration of illness was 83.4 months. 34 patients $(61.8 \%)$ underwent whitehead surgery using a Ligasure vessel sealing device and 21 patients $(38.2 \%)$ used a homemade pestle. The amount of blood loss, surgery time, and postoperative pain of the group using Ligasure was shorter than that of using the pestle $(p<0.05)$. Early complications $27.3 \%$. The average follow-up time was 15.4 months, late complications were $7.3 \%$, no recurrence. $98.8 \%$ had complete anal autonomy at the end of the study. Conclusion: Whitehead's hemorrhoidectomy is an effective method in the treatment of grade IV mixed ring hemorrhoids with a low rate of complications and recurrence. The application of Whitehead's hemorrhoidectomy with supporting instruments or vessel sealing devices depends on the surgeon's habits.

\section{I. ĐẶT VẤN ĐỀ}

Trĩ là tình trạng bệnh lý thường gặp trên lâm sàng và xảy ra ở mọi lứa tuổi, trong đó tỷ lệ mắc bệnh ở nhóm trên 40 tuổi vào khoảng 58\% [7]. Trĩ vòng hỗn hợp độ IV là một trong những tổn thương trĩ phức tạp, chiếm hết chu vi ống hậu môn, do vậy vẫn còn nhiều tranh luận về lựa chọn kĩ thuật cắt trĩ thực sự hiệu quả đối với trĩ những trường hợp này [6]. Năm 1882, Whitehead W. lần đầu mô tả kỹ thuật cắt bỏ toàn bộ trĩ vòng với một đường rạch ở niêm mạc, sau đó phẫu tích lớp niêm mạc kèm những 